\title{
Optimising management of oligohydramnios
}

\author{
Meetanpreet, Ripan Bala, Preet Kamal, Madhu Nagpal \\ Correspondence: Ripan Bala, Associate Professor, Department of Obstetrics and \\ Gynaecology, Sri Guru Ram Das Institute of Medical Sciences and Research, Vallah, \\ Amritsar, India; Email - ripanchanana@yahoo.co.in
}

Distributed under Creative Commons Attribution-Share Alike 4.0 International.

\begin{abstract}
Objectives: This study is carried out to observe the feto-maternal outcome with optimal management of oligohydramnios after 28 weeks of gestation. Methodology: The present study was conducted on 50 pregnant women with oligohydramnios at admission confirmed on ultrasound by amniotic fluid index (AFI) after 28 weeks of gestation. Bed rest, daily foetal movement count, regular nonstress test (NST), weekly or as indicated doppler, high protein infusions, hydration and appropriate diet was given. Outcome in the form of mode of delivery, APGAR score of neonate and NICU stay was studied. Results: In the presence of oligohydramnios without any opportunity to do therapeutic intervention, $90.9 \%$ subjects underwent caesarean section. In the presence of anhydramnios, $75 \%$ underwent caesarean section. Out of these, half of the babies were still born or died during NICU stay in spite of rigorous management. Intervention and optimization could be done in 46 women with resultant improved AFI in 35 cases. Out of the improved AFI cases with optimization 31.5\% underwent caesarean section and $68.6 \%$ delivered normally. Only $8.6 \%$ needed short NICU stay. In the presence of persistent oligohydramnios, calcific changes and degenerations were seen in $63.6 \%$ of placentae on histopathology examination. In cases where liquor became adequate, placental changes were seen in $8.6 \%$ only. Conclusion: Outcome of oligohydramnios pregnancy can be altered by vigorous management and antenatal supervision leading to decreased NICU admissions with better perinatal outcome.
\end{abstract}

Keywords: Amino acid infusion, oligohydramnios, NICU admissions, perinatal outcome.

The amniotic fluid which surrounds developing fetus in amniotic sac provides several benefits to the fetus. The appreciation of importance of amniotic fluid volume as an indicator of fetal status and oligohydramnios as an indicator of chronic fetal hypoxia is a relatively recent concept. The progressive improvements in ultrasonographic techniques have made it possible to assess the amniotic fluid volume nearly accurately. An amniotic fluid volume more than two standard deviation below the mean for specific gestational age or volume reduced below the 5th percentile for particular gestational age would define oligohydramnios ${ }^{1}$. The reduction in amniotic fluid early in the gestational age can interfere with fetal development leading to structural malformations. These include cranial, facial and skeletal deformities

Received: $4^{\text {th }}$ April 2017. Accepted: $15^{\text {th }}$ May 2017.

Meetanpreet, Bala R, Kamal P, Nagpal M. Optimising management of oligohydramnios. The New Indian Journal of OBGYN. 2017; 4(1):59-65 
and pulmonary hypoplasia.

Oligohydramnios is associated with variety of ominous pregnancy outcomes, such as fetal distress, low birth weight, perinatal morbidity, mortality and increased incidence of caesarean section ${ }^{2,3}$. For cases with diagnosed late onset oligohydramnios, hospitalization for close monitoring, intense antepartum assessment and optimisation is required. If any signs of fetal compromise are present immediate delivery should be considered. The decision of termination of pregnancy is very crucial since etiological factors also need to be managed besides keeping the end results of oligohydramnios in consideration. This study was done to see the fetomaternal outcome with optimal management of oligohydramnios after 28 weeks of gestation.

\section{Method}

This study was conducted on 50 subjects with oligohydramnios confirmed on ultrasound by parameter of amniotic fluid index after 28 weeks of gestation. Patients with singleton pregnancy, those deserving admission and optimization were included. At the time of admission a detailed history of the patient including her obstetric history, menstrual history, family history and personal history was taken and gestational age was recorded. Mistaken dates were ruled out. A history of draining $\mathrm{p} / \mathrm{v}$ was also ruled out. General physical examination was done and detailed serial obstetrical examination findings including clinically measured fundal height, symphisio fundal height in $\mathrm{cms}$, abdominal girth, presentation and estimated amount of liquor was recorded. The estimated foetal weight was calculated with Johnson's formula. Periodical foetal growth assessment was done. These parameters were duly watched and gravidogram updated weekly.

Laboratory parameters studied at the time of admission were: complete blood count, urine complete examination and culture sensitivity, thyroid profile, oral glucose tolerance test, viral markers, specific case related investigations like renal function test, liver function test, fundus examination which were serially repeated. Ultrasonography for fetal wellbeing was done for assessing mean gestational age, amniotic fluid index, estimated fetal weight, placental localization. Serial scans were done so as to see the effect of interventions. Biophysical profile was done to evaluate response to management therapy. Color doppler was done in suitable subjects to study vascular sufficiency of uterofetoplacental unit. The findings were utilized for decision making for terminating pregnancy. The investigations were directed in order to find out the cause of early or late onset oligohydramnios. Thus the subjects were under strict antepartum surveillance. Daily movements were recorded, regular NST was done.

IV alamine was infused every alternate day and maternal hydration was maintained. Along with Lycopene and Arginine sachets were prescribed. Females up to 34 weeks of gestation at the time of admission were given two dose of Betamethasone $12 \mathrm{mg}$ intramuscularly each after ruling out contraindications 24 hours apart. Maternal hydration by improving maternal fluid volume or decreasing maternal osmolality may be effective in improving amniotic fluid volume. Use of lycopene appears to help prevent inadequate growth of the foetus. The role of Larginine in improving growth was not quickly transferrable to the results of study because of short duration but is supportive and cost effective. There is strong reason to use corticosteroids coverage as there is evidence to suggest that antenatal corticosteroids are effective not only in reducing respiratory distress syndrome but also in reducing other complications of prematurity such as intraventricular hemorrhage.

A written informed consent was taken from the patient/husband/relatives after detailed counseling. The maternal and fetal risks were counseled as per high risk factors. The provision of neonatologist and intensive neonatal care facilities was ensured. All high risk cases were supervised with senior faculty in the department of obstetrics and pediatrics. Neonatal record for first week of life was included for immediate review. The placental morphological study and histopathology was conducted for cause related correlation. 
Chi square test was applied to compare the results with /without optimization. The detailed recordings were under close scrutiny and audit periodically.

\section{Results}

In the present study following results have been observed; $80 \%$ patients were of the age group 21-30

Table 1: Distribution of age, gravidity, incidence of hypertension

\begin{tabular}{lll}
\hline Category & & Number (\%) \\
\hline Age & $\leq 20 \mathrm{yrs}$ & $3(6 \%)$ \\
& $21-25 \mathrm{yrs}$ & $25(50 \%)$ \\
& $26-30 \mathrm{yrs}$ & $15(30 \%)$ \\
Gravidity & $>30 \mathrm{yrs}$ & $7(14 \%)$ \\
& 1 & $28(56 \%)$ \\
& 2 & $13(26 \%)$ \\
& 3 & $8(16 \%)$ \\
Incidence of & 4 & $1(2 \%)$ \\
hypertension & Normotensive & $40(80 \%)$ \\
& Hypertensive & $10(20 \%)$ \\
\hline
\end{tabular}

years, $56 \%$ subjects were primigravida and $80 \%$ subjects were normotensive (table 1). After optimization, in $70 \%$ cases AFI improved whereas in 8 $\%$ cases no opportunity of optimization was there so

Table 2: Outcome of optimization of oligohydramnios cases

\begin{tabular}{lll}
\hline Category & & Number (\%) \\
\hline Optimization & AFI improved & $35(70 \%)$ \\
attempted & AFI not improved & $11(22 \%)$ \\
$\begin{array}{l}\text { No optimization } \\
\text { opportunity }\end{array}$ & AFI same & $4(8 \%)$ \\
Total & & $50(100 \%)$ \\
\hline
\end{tabular}

AFI remained unchanged (table 2). In the presence of oligohydramnios $54.5 \%$ had a non-reactive NST whereas in case of adequate liquor $2.9 \%$ had nonreactive NST (table 3). In anhydramnios $75 \%$ had doppler changes. In cases with adequate liquor 100\% had normal doppler study (table 3 ). In the presence of adequate liquor $31.5 \%$ underwent a caesarian section and $68.6 \%$ delivered normally whereas $90.9 \%$ underwent caesarian section and $9.1 \%$ delivered normally in the presence of oligohydramnios.
In the oligohydramnios fraction $63.6 \%$ suffered from low birth weight whereas $36.4 \%$ had normal birth weight. Where AFI was less $75 \%$ had low birth weight and $25 \%$ were normal. In mothers who had normal liquor delivered healthy babies (table 3 ). In the presence of oligohydramnios $72.7 \%$ babies had APGAR 7 or less than seven at 1 minute. Only $27.3 \%$ cases had APGAR more than 7. In anhydramnios 75\% cases had APGAR above seven and 25\% had APGAR 7 and less than 7 and in the presence of normal AFI 97.1\% babies had APGAR more than 7 at 1 minute.

In the present study of oligohydramnios NICU admissions were seen in $90.9 \%$ cases. In cases of anhydramnios, NICU admissions rose to $75 \%$. In cases where liquor was normal, $91.4 \%$ babies were bedside and only $8.6 \%$ needed NICU admission. In the presence of oligohydramnios, $36.4 \%$ babies expired. Only $9.1 \%$ cases did not require admission and $54.5 \%$ were discharged after being admitted for a variable number of days in NICU. In cases of anhydramnios $50 \%$ cases expired. In cases where liquor was normal $91.4 \%$ did not require admission. Non expired and only $8.6 \%$ needed NICU admission (table 3 ).

In the presence of oligohydramnios calcific changes and degenerations were seen in $63.6 \%$ of placentae on histopathologic examination. In cases of anhydramnios calcific changes and degenerations were seen in $50 \%$ of placentae on histopathologic examination. In cases where liquor was normal, $91.4 \%$ placentae did not show any changes whereas in $8.6 \%$ placental changes were seen (table 3 ).

Hypertension (HTN) was associated with a perinatal mortality of $20 \%$ whereas in the absence of HTN the mortality was $10 \%$. In the presence of HTN NICU admission was $50 \%$ whereas in the absence the admission rate was $12.5 \%$ (table 4 ). In the absence of HTN $77.5 \%$ needed no admission. In this study, calcific and degenerative changes were seen in $80 \%$ of placentae on histopathologic examination in presence of hypertension. In the absence of HTN calcific and degenerative changes i.e. infarction, villous fibrinoid necrosis, villous hypermaturity, avascular villi, calcifications, lymphohistiocyticvillitis, and thickened 
Table 3: Relation between AFI and Non stress test, Doppler changes, Mode of delivery, LBW, APGAR Score, NICU Admission, Neonatal outcome, Placental changes.

\begin{tabular}{|c|c|c|c|c|c|}
\hline Categories & & $\begin{array}{l}\text { AFI } \\
\text { improved after } \\
\text { optimization } \\
\text { Less AFI } \\
(\mathrm{N}=11)\end{array}$ & $\begin{array}{l}\text { No optimization } \\
\text { opportunity } \\
\text { Liquor less } \\
\text { (Anhydramnios) } \\
(\mathrm{N}=4)\end{array}$ & $\begin{array}{l}\text { AFI improved } \\
\text { after } \\
\text { optimization } \\
\text { Normal AFI } \\
(\mathrm{N}=35)\end{array}$ & $P$ value \\
\hline \multirow[t]{2}{*}{ Non stress test } & Reactive & $5(45.5 \%)$ & $2(50 \%)$ & $34(97.1 \%)$ & 0.0001 \\
\hline & Non reactive & $6(54.5 \%)$ & $2(50 \%)$ & $1(2.9 \%)$ & \\
\hline \multirow[t]{2}{*}{ Doppler changes } & No changes & $5(45.5 \%)$ & $1(25 \%)$ & $35(100 \%)$ & $<0.0001$ \\
\hline & Change present & $6(54.5 \%)$ & $3(75 \%)$ & 0 & \\
\hline \multirow[t]{2}{*}{ Mode of delivery } & LSCS & $10(90.9 \%)$ & $3(75 \%)$ & $11(31.5 \%)$ & 0.0014 \\
\hline & NVD & $1(9.1 \%)$ & $1(25 \%)$ & $24(68.6 \%)$ & \\
\hline \multirow[t]{2}{*}{ Low birth weight } & No & $4(36.4 \%)$ & $1(25 \%)$ & $35(100 \%)$ & $<0.0001$ \\
\hline & Yes & $7(63.6 \%)$ & $3(75 \%)$ & 0 & \\
\hline APGAR Score at & $\leq 7$ & $8(72.7 \%)$ & $1(25 \%)$ & $1(2.9 \%)$ & $<0.0001$ \\
\hline 1 minute & $>7$ & $3(27.3 \%)$ & $3(75 \%)$ & $34(97.1 \%)$ & \\
\hline APGAR Score at & $\leq 7$ & $9(81.9 \%)$ & $3(75 \%)$ & $1(2.9 \%)$ & $<0.0001$ \\
\hline 5 minute & $>7$ & $2(18.1 \%)$ & $1(25 \%)$ & $34(97.1 \%)$ & \\
\hline \multirow[t]{2}{*}{ NICU Admission } & No & $1(9.1 \%)$ & $1(25 \%)$ & $32(91.4 \%)$ & $<0.0001$ \\
\hline & Yes & $10(90.9 \%)$ & $3(75 \%)$ & $3(8.6 \%)$ & \\
\hline Neonatal & Discharged & $6(54.5 \%)$ & $1(25 \%)$ & $3(8.6 \%)$ & $<0.0001$ \\
\hline \multirow[t]{2}{*}{ outcome } & Expired & $4(36.4 \%)$ & $2(50 \%)$ & 0 & \\
\hline & No admission & $1(9.1 \%)$ & $1(25 \%)$ & $32(91.4 \%)$ & \\
\hline \multirow[t]{2}{*}{ Placental changes } & Change present & $7(63.6 \%)$ & $2(50 \%)$ & $3(8.6 \%)$ & $<0.0001$ \\
\hline & Normal & $4(36.4 \%)$ & $2(50 \%)$ & $32(91.4 \%)$ & \\
\hline
\end{tabular}

Table 4: Relationship between pre eclampsia and perinatal outcome

\begin{tabular}{|c|c|c|c|c|c|}
\hline \multirow{2}{*}{$\begin{array}{l}\text { Pre } \\
\text { eclampsia/ } \\
\text { Hypertension }\end{array}$} & \multicolumn{3}{|c|}{ Perinatal outcome } & \multirow{2}{*}{$\begin{array}{l}\text { Total } \\
\text { Number } \\
(\%)\end{array}$} & \multirow{2}{*}{$\begin{array}{l}P \\
\text { value }\end{array}$} \\
\hline & $\begin{array}{l}\text { Discharged } \\
\text { Number }(\%)\end{array}$ & $\begin{array}{l}\text { Expired } \\
\text { Number }(\%)\end{array}$ & $\begin{array}{l}\text { No admission } \\
\text { Number }(\%)\end{array}$ & & \\
\hline Absent & $5(12.5 \%)$ & $4(10 \%)$ & $31(77.5 \%)$ & $40(100 \%)$ & 0.011 \\
\hline Present & $5(50 \%)$ & $2(20 \%)$ & $3(30 \%)$ & $0 \%)$ & \\
\hline Total & $10(20 \%)$ & $6(12 \%)$ & $34(68 \%)$ & $50(100 \%)$ & \\
\hline
\end{tabular}

women were primigravidas followed by $46 \%$ multigravidas ${ }^{4}$. These results are comparable with this study and suggest

vessels were seen in $10 \%$ of placentae on histopathologic examination.

\section{Discussion}

In the present study $80 \%$ patients were of the age group 21-30 years. In a study conducted by Bangal et al $78 \%$ women with oligohydramnios were in the age group of 20-29 years ${ }^{4}$ and the above results were comparable. These results indicate that oligohydramnios is more common in age group upto 30 years. In a study conducted by Bangal et al, $54 \%$ that the incidence of oligohydramnios is slightly more in primigravidas than multigravidas.

In our study, $80 \%$ subjects were normotensive. Bangal et al, also observed $16 \%$ hypertensive pregnancies complicated with oligohydramnios ${ }^{4}$. The results were comparable and hence a definitive relation can be established between pregnancy induced hypertension and oligohydramnios. Hypertensive disorders which cause chronic placental insufficiency lead to oligohydramnios. In the oligohydramnios group $32.5 \%$ had mild or severe preeclampsia compared to 
$38.46 \%$ and $31 \%$ of oligohydramnios group in study by Chandra et $\mathrm{al}^{5}$ and Sriya et $\mathrm{al}^{6}$. Any cause of chronic placental insufficiency including chronic abruptio and diabetes mellitus can cause fetal growth restriction and oligohydramnios in term pregnancies. The incidence of PIH was high in the study group. Hence PIH can be attributed to be one of the aetiological factors for oligohydramnios.

The non-reactive non stress test rates were high in women with AFI $<5 \mathrm{~cm}$. which is more or less similar to the incidence reported by the studies of Chandra et $\mathrm{al}^{5}$, Sriya et $\mathrm{al}^{6}$, Kumar et $\mathrm{al}^{7}$ and Patil et $\mathrm{al}^{8}$. Therefore, patients with severe oligohydramnios with $\mathrm{AFI}<5$ should undergo antepartum management in the form of induction of labor in order to improve their perinatal outcome. In the presence of oligohydramnios $54.5 \%$ had color doppler changes and in cases with adequate liquor $100 \%$ had normal doppler study which is comparable to the study of Caroll et al and Hackett et al $^{9,10}$.

In the present study, $90.9 \%$ underwent a caesarean section and $9.1 \%$ delivered normally in the presence of oligohydramnios whereas $31.5 \%$ underwent caesarean section and $68.6 \%$ delivered normally in the case of adequate liquor. In a clinical study of oligohydramnios, mode of delivery and perinatal outcome reported by Madhavi et al ${ }^{11}$ the incidence of caesarean section was $75 \%$ alike of present study. In a study of effect of amniotic fluid index on mode of delivery by Patil et al it was concluded that oligohydramnios is associated with increased rate of caesarean section with fetal distress as most common indication ${ }^{8}$.

In our study, in the oligohydramnios fraction $63.6 \%$ suffered from low birth weight whereas $36.4 \%$ had normal birth weight. Where AFI was less $75 \%$ had low birth weight and $25 \%$ were normal. In mothers who had normal liquor delivered healthy babies similar to the study done by Chandra et al, Sriya et al and Casey et al ${ }^{5,6,12}$.

Chauhan et al. in their meta-analysis found that intrapartum $\mathrm{AFI} \leq 5$ was associated with increased risk of caesarean section for fetal distress which was similar to this study. When the secondary outcome was measured, significant correlation was found in terms of Non-reactive NST and admission to the NICU ${ }^{13}$.

As per table 3, in the presence of oligohydramnios $72.7 \%$ babies had APGAR $\leq 7$ at 1 minute. Only $27.3 \%$ cases had APGAR more than 7. In anhydramnios $75 \%$ cases had APGAR above seven and 25\% had APGAR $\leq 7$ and in the normal AFI 97.1\% babies had APGAR more than 7 at 1 minute. In the presence of oligohydramnios, $81.9 \%$ babies had APGAR $\leq 7$ at 5 minutes. Only $18.1 \%$ cases had APGAR more than 7. In anhydramnios $25 \%$ cases had APGAR above 7 at 5 minutes. In case of normal AFI $97.1 \%$ babies had APGAR more than 7 at 5 minutes and 2.9\% cases had APGAR $\leq 7$. These results are not consistent with the studies reported by Sriya et al, Chandra $\mathrm{P}$ et al and Rutherford et al ${ }^{5,6,14}$.

In the present study of oligohydramnios NICU admissions were seen in $90.9 \%$ cases. In cases of anhydramnios NICU admissions were raised to $75 \%$. In cases where liquor was normal, $91.4 \%$ babies were bedside and only $8.6 \%$ needed NICU admission. Forty percent of newborns were admitted in neonatal ward for various morbidities like neonatal seizures, birth asphyxia, meconium aspiration etc. This is not consistent with studies by Casey et al and Magann et al 12, 15. However, both authors refer to admission to neonatal intensive care units. Study by Sriya et al ${ }^{6}$ showed even higher incidence of $(88.88 \%)$ admission to neonatal ward. In Chandra et al ${ }^{5}$ study neonatal death occurred in one case. In study by Baron et al ${ }^{16}$ and Casey et al ${ }^{12}$ there was no mortality probably because of good neonatal intensive care unit facilities. All the 6 deaths in present study group were early neonatal deaths and were un-booked cases.

In our study HTN was associated with a perinatal mortality of $20 \%$ whereas in the absence of HTN the mortality was $10 \%$. In the presence of HTN NICU admission was $50 \%$ whereas in the absence the admission rate was $12.5 \%$. In a study by Singhal et al the NICU admission rate was $71.43 \%$. Low birth weight was seen in $66 \%$ and birth asphyxia in $52.4 \%$ of 
cases ${ }^{17}$.

In the presence of oligohydramnios calcific changes and degenerations were seen in $63.6 \%$ of placentae on histopathologic examination. $36.4 \%$ were normal. In cases of anhydramnios calcific changes and degenerations were seen in $50 \%$ of placentae on histopathologic examination. In cases where liquor was normal, $91.4 \%$ placentae did not show any changes whereas in $8.6 \%$ placental changes were seen. In the absence of HTN calcific and degenerative changes i.e. infarction, villous fibrinoid necrosis, villous hypermaturity, avascular villi, calcifications, lymphohistiocyticvillitis, and thickened vessels were seen in $10 \%$ of placentae on histopathologic examination. Similar to changes found in the placentae as reported by Krielessi et al ${ }^{18}$ and Majumdar et al ${ }^{19}$.

\section{Conclusion}

From the present study it can be concluded that along with maternal and fetal surveillance, vigorous supervision and management of the case can help in the alteration of outcome of oligohydramnios pregnancy in a positive way. However every optimization intervention is debated for its use efficacy, still undertaken to give improved results practically. It should be attempted to achieve better outcome of oligohydramnios pregnancy. Per se, no guidelines are there for managing isolated oligohydramnios which is encountered very often in clinical practice. Optimization should be offered wherever lies the opportunity to do it.

\section{Conflict of interest: None. Disclaimer: Nil.}

\section{References}

1.Phelan JP, Smith CV, Small M. Amniotic fluid volume assessment with four quadrant technique at 36-42 wks gestation. J Repod Med. 1987; 32: 540-2.

2.Chamberlain PF, Manning FA, Morrison I, Harman CR, Lange IR. Ultrasound evaluation of amniotic fluid volume. Am J Obstet Gynaecol. 1984; 150: 245-9.

3.Banks EH, Miller DA. Perinatal risks associated with borderline AFI. Am J Obstet Gynaecol. 1999; 18: 1461-3.
4.Bangal VB, Giri PA, Sali BM. Incidence of oligohydramnios during pregnancy and its effects on maternal and perinatal outcome. J Pharmaceut Biomed Sci. 2011;12(12):1-4.

5.Chandra P, Kaur SP, Hans DK, Kapila AK. The impact of amniotic fluid volume assessed intrapartum on perinatal outcome. Obstet and Gynae Today. 2000; 5(8): $478-81$.

6.Sriya R, Singhai S. Perinatal outcome in patients with amniotic fluid index $<5 \mathrm{~cm}$. J Obstet and Gynaecol of India. 2001; 51(5): 98-100.

7.Kumar P, Iyer S, Ramkumar V. Amniotic fluid index A new ultrasound assessment of amniotic fluid. J Obstet and Gynaecol of India. 1991; 41(1):10-12.

8.Patil AB, Metkar S, Singh S. A study of effect of amniotic fluid index on mode of delivery. International Journal of Recent Trends in Science and Technology. 2015; 14(3): 567-70.

9.Carroll BC, Bruner JP. Umbilical artery Doppler velocimetry in pregnancies complicated by oligohydramnios. J Reprod Med. 2000; 45(7): 562-66.

10.Hackett GA, Nicolaides KH, Campbell S. Doppler ultrasound assessment of fetal and uteroplacental circulations in severe second trimester oligohydramnios. Br J Obstet Gynae. 1987; 94(11): 1074-77.

11.Madhavi K, Rao PC. Clinical Study of Oligohydramnios, Mode of Delivery and Perinatal Outcome. IOSR Journal of Dental and Medical Sciences. 2015; 14(4): 6-11.

12.Casey BM, McIntire DD, Donald D. Pregnancy outcome after diagnosis of oligohydramnios at or beyond 34 weeks of gestation. Am J Obstet Gynecol. 2000; 182(4): 902-12.

13.Chauhan SP, Sanderson M, Hendrix NW. Perinatal outcome and amniotic fluid index in the antepartum and intrapartum periods: a meta-analysis. Am J Obstet Gynecol. 1999; 181(6): 1473-78.

14.Rutherford SE, Jeffrey P, Phelan J, Smith CV, Jacobs $\mathrm{N}$. The four quadrant assessment of amniotic fluid volume: An adjunct to antepartum fetal heart rate testing. Obstet Gynecol. 1987; 70: 353.

15.Magann EF, Kinsella MJ, Chouhan SP, McNamara MF, Gehring BW, Morrison JC. Does an amniotic fluid index of $\leq 5 \mathrm{~cm}$ necessitate delivery in high risk pregnancies ? A case control study. Am J Obstet Gynecol. 
1999; 180 (6pt1): 1354-59.

16.Baron C, Morgan MA, Garite TJ. The impact of amniotic fluid volume assessed intraparum on perinatal outcome. Am J Obstet Gynaecol.1995; 173(1): 167-74.

17.Singhal SR, Anshu D, Nanda S. Maternal and perinatal outcome in severe pre eclampsia and eclampsia. South Asian Federation of Obs and Gynae. 2009; 1(3): 25-8.

18.Krielessi V, Papantoniou N, Papageorgiou I, Chatzipapas I, Manios E, Zakopoulos N, Antsaklis A. Placental Pathology and Blood Pressure's Level in Women with Hypertensive Disorders in Pregnancy. J Obstetrics and Gynecology International. 2012; 1-6.

19.Majumdar S, Dasgupta H, Bhattacharya K, Bhattacharya A. A Study of Placenta in Normal and
Hypertensive Pregnancies. J Anat Soc India. 2005; 54(2):1-9.

Meetanpreet $^{1}$, Ripan Bala ${ }^{2}$, Preet Kamal ${ }^{3}$, Madhu Nagpal $^{4}$

${ }^{1}$ Junior Resident, ${ }^{2}$ Associate Professor, ${ }^{3}$ Assistant Professor, ${ }^{4}$ Professor and Head, Department of Obstetrics and Gynaecology, Sri Guru Ram Das Institute of Medical Sciences and Research Vallah, Amritsar,India 